\title{
Prehospital pediatric trauma classification (PHPTC) as a tool for optimizing trauma care resources in the city of São Paulo, Brazil ${ }^{1}$
}

\author{
Classificação do atendimento pré-hospitalar pediátrico como instrumento para otimizar \\ a alocação de recursos no atendimento do trauma na cidade de São Paulo, Brasil
}

\author{
Simone de Campos Vieira Abib ${ }^{2}$, Sergio Tomaz Schettini ${ }^{3}$, Luiz Francisco Poli de Figueiredo ${ }^{4}$ \\ 1. Doctoral Thesis, Pediatric Surgery, Federal University of São Paulo (UNIFESP). São Paulo, Brazil. \\ 2. Doctoral Fellow and Attending Physician, Surgical Techniques and Experimental Surgery, Department of Surgery, UNIFESP. São Paulo, Brazil. \\ 3. Associate Professor, Pediatric Surgery, Department of Surgery, UNIFESP. São Paulo, Brazil. \\ 4. Chairman, Surgical Techniques and Experimental Surgery, Department of Surgery, UNIFESP. São Paulo, Brazil.
}

\begin{abstract}
Purpose: To evaluate the pediatric prehospital care in São Paulo, the databases from basic life support units (BLSU) and ALSU, and to propose a simple and effective method for evaluating trauma severity in children at the prehospital phase. Methods: A single firemen headquarter coordinates all prehospital trauma care in São Paulo city. Two databases were analyzed for children from 0 to 18 years old between 1998 and 2001: one from the Basic Life Support Units (BLSU - firemen) and one from the Advanced Life Support Units (ALSU - doctor and firemen). During this period, advanced life support units provided medical reports from 604 victims, while firemen provided 12.761 reports (BLSU+ALSU). Pre-Hospital Pediatric Trauma Classification is based on physiological status, trauma mechanism and anatomic injuries suggesting high energy transfer. In order to evaluate the proposed classification, it was compared to the Glasgow Coma Score and to the Revised Trauma Score. Results: There was a male predominance in both databases and the most common trauma mechanism was transport related, followed by falls. Mortality was $1.6 \%$ in basic life support units and $9.6 \%$ in ALSU. There was association among the proposed score, the Glasgow Coma Score and to the Revised Trauma Score $(\mathrm{p}<0.0001)$. Conclusion: PreHospital Pediatric Trauma Classification is a simple and reliable method for assessment, triage and recruitment of pediatric trauma resources.
\end{abstract}

Key words: Epidemiology. Mortality. Trauma. First Aid. Child.

\begin{abstract}
RESUMO
Objetivo: Avaliar o atendimento pré-hospitalar de crianças e adolescentes em São Paulo, avaliar o banco de dados das Unidades de Suporte Básico (UR) e Avançado (USA) e propor um método simples e eficaz para a avaliação da gravidade do trauma pediátrico na fase pré-hospitalar. Métodos: Uma única central do Corpo de Bombeiros (COBOM) coordena todo o atendimento pré-hospitalar em São Paulo. Dois bancos de dados foram analisados para crianças de 0 a 18 anos de idade, entre 1998 e 2001: um das Unidades de Suporte Básico de Vida (UR- bombeiros) e outra de Unidades de Suporte Avançado (USA- médico e bombeiros). Neste período, o Serviço de Atendimento Médico de Urgência do Estado de São Paulo (SAMU) forneceu relatórios médicos de 604 vítimas, enquanto os bombeiros forneceram relatórios de 12.761 vitimas (UR+USA). A classificação do trauma pré-hospitalar pediátrico é baseada na condição fisiológica, mecanismo de trauma e lesões anatômicas das vítimas. A classificação do trauma pré-hospitalar pediátrico foi comparada à Escala de Coma de Glasgow (GCS) e ao Escore de Trauma Revisado (RTS). Resultados: Houve predominância do sexo masculino em ambos bancos de dados. O mecanismo de trauma mais freqüente foi relacionado a transporte, seguido de quedas. A mortalidade foi 1,6\% nas Unidades Básicas e 9,6\% no Suporte Avançado. Houve associação entre a classificação do trauma préhospitalar pediátrico, Escala de Coma de Glasgow (GCS) e ao Escore de Trauma Revisado (RTS) GCS e RTS (p<0,0001). Conclusão: A classificação do trauma pré-hospitalar pediátrico é um método simples e confiável para a avaliação, triagem e recrutamento de recursos para o atendimento pré-hospitalar do trauma pediátrico.
\end{abstract}

Descritores: Epidemiologia. Mortalidade. Trauma. Primeiros Socorros. Criança. 


\section{Introduction}

Prehospital trauma care in children remains a significant problem worldwide. ${ }^{1,2-7}$ Although health personnel are used to dealing with bizarre situations at the trauma scene, whenever the victim is a child, emotional involvement and reactions may be quite different than those involving adults. Moreover, a frightened child will hardly cooperate with the team; vital signs are more difficult to obtain and normal values vary according to age. These drawbacks contribute to deficits in trauma databases. Additionally, international trauma scores used for adults have major limitations when applied to children, especially the anatomic ones, which should not be used in the prehospital phase, since the final diagnosis is yet to be made. Trauma is an epidemic disease in Brazilian large cities. In the city of São Paulo (17 million inhabitants), there are about 420 calls a day for prehospital care. Children and adolescents represent less than $5 \%$ of all prehospital care. Literature has not yet established the criteria for dispatching advanced life support units (ALSU) and air transportation for children, neither has it agreed about training and protocols for database in childhood trauma. A preliminary evaluation detected major deficiencies in the database of patients aged zero to 18 years. To establish the current status of prehospital care of approximately 13000 pediatric victims in São Paulo, there was a need to create a severity score to address potential problems and propose future interventions. Our goals were to evaluate the prehospital care of children and adolescents in the city of São Paulo, the databases from basic life support units (BLSU) and ALSU, and to propose a simple and effective method for evaluating trauma severity in children at the prehospital phase.

\section{Methods}

A single firemen central headquarter coordinates all prehospital trauma care in São Paulo city. Thus, firemen database include both ALSU and BLSU dispatches. There are 40 BLSU with three firemen in each unit. Four ALSU and one helicopter have one firemen, a doctor and a nurse in each one. Helicopter is available only during the day, for security reasons. Two databases were analyzed from prehospital care for children from 0 to 18 years old in a fouryear period (1998 to 2001). During this period, ALSU provided medical reports from 604 victims, while firemen provided 12.761 reports (BLSU+ALSU). Prehospital care for this age range represents $2.12 \%$ of all BLSU+ALSU database and $4.14 \%$ of ALSU dispatches. In order to compare them and to estimate the severity of trauma, a prehospital pediatric trauma classification (PHPTC) was proposed, based on the physiological status, trauma mechanism and anatomic injuries suggesting high energy transfer. There are three severity categories as follows:

- Mild was considered in the presence of isolated abrasions and wounds, bites, stable vital signs, fractures of hand and feet bones, no altered level of consciousness and trauma mechanism suggesting low transfer of energy.

- Potential risk was considered when the trauma mechanism suggested high transfer of energy as well as femur, pelvis and long bone fractures, cervical pain or suspected medullar or abdominal injuries, risk of airway obstruction, traumatic amputation, pneumotorax, mild head trauma and ALSU dispatch.

- Severe was considered whenever there was a multisystemic trauma, loss of or altered level of consciousness, shock and respiratory impairment.

- Undetermined was considered when information was lacking.

Victims were also evaluated by sex, age, timing of response, trauma mechanism, type of injuries, vital signs and mortality. Glasgow coma score (GCS) and revised trauma score (RTS), whenever available, were correlated used to correlate to our proposed score. As for GCS, we followed the ATLS classification for head trauma, considering 14-15 as mild, 9-13 as moderate and 3-8 as severe. ${ }^{8}$ An RTS from 04 was considered severe, from 5-6 moderate and 7 or more was considered as mild. The type of accident was classified into four subgroups as follows: transport related, falls, intentional and others. All motor vehicle crashes, train, bike, motorcycle, as well as pedestrian accidents were considered transport related. Intentional events were suicides, homicides and aggression. ALSU database allowed RTS calculation and to determine mortality at scene, during transportation and at emergency room admission. Only overall mortality could be stated from firemen's database. Additionally, respiratory rate was also absent; therefore RTS could not be calculated. Based on the trauma mechanism, ALSU dispatch adequacy was also evaluated. The utilization of ALSU was considered inadequate when the victim presented only mild injuries without severe or potential risk trauma criteria. We considered it as adequate in severe trauma victims or potential for severe trauma situations, when the firemen protocol includes the use of ALSU. In these situations, the use of ALSU for mild trauma victims was considered justifiable. Statistical analysis was performed using $t$ Student, Chi-square, two-way analysis of variance for repeated measures (ANOVA) with BrownForsythia's, Bonferroni's or Dunnet's tests and Kappa method. A $p$ value $<0.05$ was considered significant.

\section{Results}

In both BLSU+ALSU and ALSU databases, males were the large majority of trauma victims, as shown in table 1 . About half of the patients were 14 years old or less (Figure 1 , Table 1 ). In more than $60 \%$ of the cases the mechanism of trauma was transport related, followed by falls (Table 1). Intentional events were related to major severity $(p<0.0001)$. In the BLSU+ALSU database, GCS was available in only $18.4 \%$ of trauma victims, $91.8 \%$ of them classified as mild. On the other hand, in ALSU reports GCS information was available in $95.9 \%$, being considered as severe or moderate in $30 \%$ of them. RTS was not calculated due to the lack of information, particularly respiratory rate, in the BLSU+ALSU database. In $73.8 \%$ of ALSU reports, RTS was possible to calculate (mean value of 6.53 ), and $27.6 \%$ of them were considered as severe. As for our proposed severity classification, $37 \%$ of ALSU reports were considered as severe and $36 \%$ as mild trauma. For ALSU+BLSU database, $61.7 \%$ were considered as mild and $6.4 \%$ as severe trauma victims. Since only $2.7 \%$ of severe trauma victims were in 
fact assisted by ALSU, we considered that the number of available ALSU is much less than ideal. The use of ALSU was considered justified in $71.8 \%$, and over-used in $28.2 \%$, when requested for mild trauma victims $(\mathrm{p}<0.0001)$. There has been a significant association between our proposed severity classification and both GCS and RTS in ALSU reports $(p<0.0001)$ as well as with GCS in BLSU+ALSU database $(p<0.0001)$, suggesting that the proposed method is valid. Mortality in BLSU+ALSU database was $1.6 \%$, with no detailed information available regarding the site of the moment of death. For ALSU cases, mortality rate was $9.6 \%$, occurring at scene in $72.4 \%$, during transportation in $5.2 \%$, and at arrival in emergency rooms in $22.4 \%$. Overall mortality was $25 \%$ for severe victims in both databases $(p<0.001)$. There has been association between death and severe trauma victims in ALSU $(\mathrm{p}<0.001)$. Only one mild victim died, all the remaining deaths were in victims considered as severe trauma. A similar finding was detected in the BLSU+ALSU database, in which no deaths occurred in mild or potential risk victims.
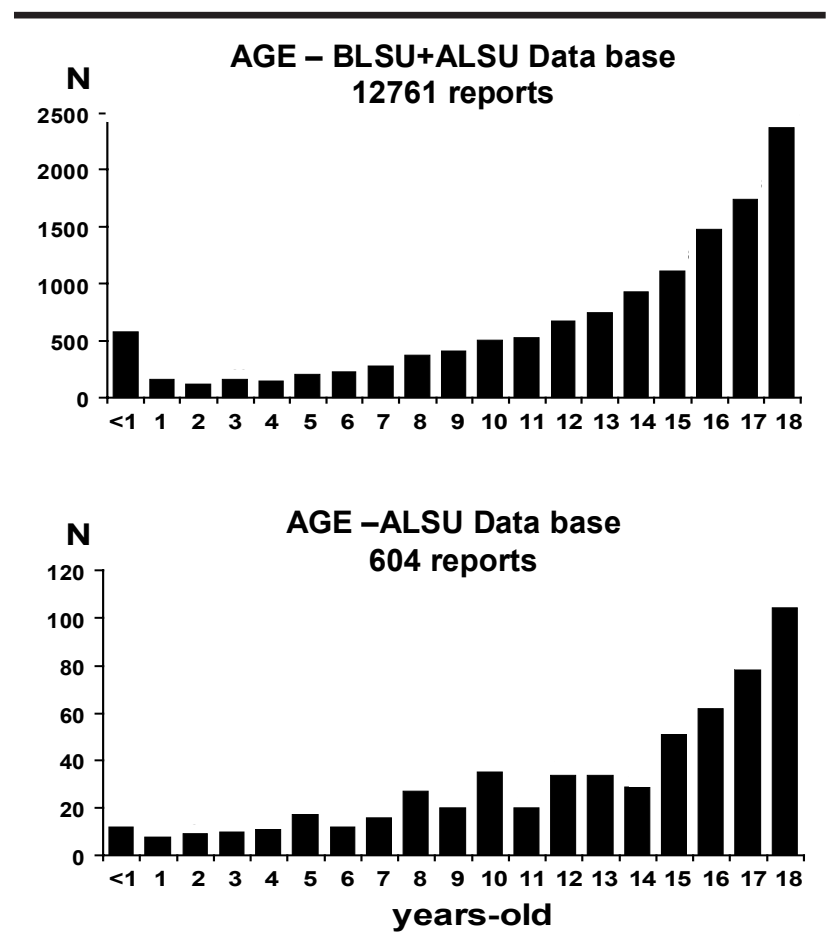

FIGURE 1 - Age distribution according to the database reports from advanced life support units (ALSU) and basic life support units (BLSU+ALSU).

TABLE 1 - Prehospital care provided by Basic Life Support Units (BLSU) and Advanced Life Support Units (ALSU) to trauma victims according to their sex, age, mechanism of trauma and mortality.

\begin{tabular}{clcc}
\hline \multicolumn{2}{c}{ Prehospital care 1998-2001 } & BSLU+ALSU (n=12.761) & ALSU (n=604) \\
\hline Sex & Male & $8907(69.8 \%)$ & $445(73.7 \%)$ \\
& Female & $3854(30.2 \%)$ & $159(26.3 \%)$ \\
\hline Age & $0-5$ years & $1378(10.8 \%)$ & $74(12.3 \%)$ \\
& 6-14 years & $4671(36.6 \%)$ & $232(38.4 \%)$ \\
& 15-18 years & $6712(52.6 \%)$ & $298(49.3 \%)$ \\
\hline Mechanism & Transport related & $8486(66.5 \%)$ & $375(62.1 \%)$ \\
of trauma & Falls & $3203(25.1 \%)$ & $106(17.6 \%)$ \\
& Intentional injuries & $357(2.8 \%)$ & $33(5.4 \%)$ \\
& Others & $715(5.6 \%)$ & $90(14.9 \%)$ \\
\hline
\end{tabular}

\section{Discussion}

Our proposed classification, based on a mixture of data from physiological status, trauma mechanism and anatomic injuries, effectively estimated trauma severity in children and adolescents. It may be useful for a rapid assessment, triage and resources allocation at the prehospital arena. Moreover, mortality among patients considered by our classification as severe trauma was $25 \%$ for both BLSU+ALSU and ALSU databases, with a significant correlation between mortality and trauma severity. The use of international trauma scores for children is neither widespread nor consensual. Most reports are limited to etiology or type of injury, rather than the desired widespread use of a reliable trauma score for pediatric population. ${ }^{9}$ Those reports also suggest that mortality and the need for hospitalization should be taken as severity indexes. Moreover, traditional indexes such as the Abbreviated Injury Scale (AIS), Revised Trauma Score (RTS), Injury Severity Score (ISS) and Maximum Abbreviated Injury Score (MAIS) and even the Pediatric Trauma Score (PTS) have limitations, especially when applied to smaller children., ${ }^{9}$, ${ }^{16}$ Although employed to address severity, Trauma ScoreInjury Severity Score (TRISS), RTS and PTS have not been tested for triage purposes. The use of anatomic scores should be avoided, since the required final diagnosis of injuries is yet to be made at hospital. As a consequence, overtriage at the prehospital scenario has been unavoidable. ${ }^{10}$ The same has been detected in our city, where children are considered as severe trauma until proven otherwise, when dispatching an ALSU. In our series, the ALSU recruitment was considered justified in $71.8 \%$, which 
could be improved substantially with the use of our severity classification for adequate dispatch in a prospective manner. The majority of trauma in our pediatric population that required prehospital assistance was transport and falls related. Intentional injuries were only $2.8 \%$ and $5.4 \%$ of all BLSU and ALSU dispatches, respectively. As for adults, the large majority of victims of intentional injuries are transported to the emergency rooms by civilians or policemen. However, those children intentionally injured showed a significant association with increased severity. Holland at al reported a similar observation. ${ }^{17}$ Prehospital mortality rates were $1.6 \%$ for BLSU+ALSU and $9.6 \%$ for ALSU database. Most deaths occurred at trauma scene (72.4\%), followed by deaths on arrival at the emergency room $(22.4 \%)$. Arreola-Risa et al suggested that mortality at scene maybe a reflection of a much longer response time, based on a comparison between Mexico city and Seattle. ${ }^{18}$ Another aspect to be considered is the destination of traumatized children. Nathens et $\mathrm{al}^{19}$ and Esposito et al ${ }^{20}$ enhances the importance of trauma systems and their impact on mortality rates. The concept is simple, but implementation requires complex structures involving law, institutional agreements and protocols. Calkins et $\mathrm{al}^{21}$ had successful results with regional care and pediatric trauma centers; however, others ${ }^{22-24}$ suggested that improve results were achieved exclusively for specific injuries such as burns and head trauma. Thus, Potoka et al ${ }^{24}$ suggest that rather than pediatric trauma centers, efforts should be driven toward training and education on pediatric trauma management for established trauma centers. There are no exclusive trauma centers in Brazil, being both traumatized adults and children treated at general hospitals. Constructing a trauma registry in our country is not an easy task. It must be well planned and should include trauma scores. Besides, a constant work must be carried out in analyzing results, so that the necessary modifications are incorporated. ${ }^{5}$ Deficiencies in registries such as the ones we detected in the present study, including the absence of height for falls, lack of information about the position of the child in the car and the use of safety tools, were also detected in most series. ${ }^{8,26-30}$ Classifying a type of event can be difficult, so that a good protocol with proper codification and adequately trained personnel is of essence. Our database did not allow us to identify cases of child abuse. Vital signs were an additional problem in our study, as was for others. ${ }^{1,3}$ The underreported and/or imprecise GCS in children was also a drawback when evaluated by firemen (BLSU), being considered as 14 or 15 in $92 \%$ of our cases. Seidel et $\mathrm{al}^{3}$ showed similar findings such as report of pulse in $76 \%$, respiratory rate in $69 \%$, arterial pressure in $59 \%$, skin color and aspect in $85 \%$, being normal in $86 \%$, and capillary refill in $8 \%$, being normal in $97.7 \%$ of their trauma victims. Moront et al $^{1}$ and Hannan et a ${ }^{13}$ suggest that better training in GCS for children is needed in prehospital phase. There were also problems with arterial pressure measurement and with the lack of proper equipment for children. Teach et $\mathrm{al}^{6}$ question the need of arterial pressure in prehospital care, as well as venous access and fluid replacement, stating that the better fluid would be gasoline for rapid hospital transport. Their series showed longer scene times (35\% longer) and little benefit for the patients. ${ }^{7}$ However, this concept in cities such as São Paulo should be considered carefully, because we have large distances and longer transportation time. There are several limitations of our study, largely related to our databases. We recommend caution in extrapolating our results to other urban and rural communities. Only a prospective evaluation can prove the usefulness of this very simple score, which allows a rapid triage as well as a satisfactory prediction of severity in traumatized children and adolescents. Our impressive numbers clearly establish trauma as an epidemic disease also among the children. ${ }^{16}$ Corrective database interventions are now being suggested to allow a reliable national registry as well as meetings are be held amongst the institutions involved to propose new protocols, which will allow us to address the potential for a widespread use and true validation of the proposed score. We are not aware of other classification aimed for the prehospital triage in children sustained trauma. The use of data from physiological status, trauma mechanism and anatomic injuries allowed us to adequately estimate trauma severity in children and adolescents.

\section{Conclusion}

Based on our findings, we believe that the proposed classification provides a simple, rapid and effective tool for the assessment, triage and resources allocation at the prehospital arena for pediatric trauma.

\section{References}

1. Moront ML, Gotschall CS, Eichelberger MR. Helicopter transport of injured children: system effectiveness and triage criteria. J Pediatr Surg. 1996;31:1183 - 8.

2. Scheidt PC, Harel Y, Trumble AC, Jones DH, Overpeck $\mathrm{MD}$, Bijur PE. The epidemiology of nonfatal injuries among US children and youth. Am J Publ Health. 1995;85:932-8.

3. Seidel JS, Henderson DP, Ward P, Wayland BW, Ness B. Pediatric prehospital care in urban and rural areas. Pediatrics. 1991;88:681-90.

4. Svenson JE, Nypaver M, Calhon R. Pediatric prehospital care: epidemiology of use in a predominantly rural state. Pediatr Emerg Care. 1996;12:173-9.

5. Sweitzer RE, Rink RD, Corey T, Goldsmith J. Children I motor vehicle collisions: analysis of injury by restraint use and seat location. J Forensic Sci. 2002;47:1049-54.

6. Teach SJ, Antosia RE, Lund P, Fleisher GR. Prehospital fluid therapy in pediatric trauma patients. Pediatr Emerg Care. 1995;11:5-8.

7. Tsai A, Kallsen G. Epidemiology of pediatric prehospital care. Ann Emerg Med. 1987;16:284-92.

8. American College of Surgeons. Committee on Trauma. Advanced Life Support for Doctors. Instructor Manual. Sixth ed. Chicago: 1997. p1000.

9. Beattie TF, Currie CE, Williams JM, Wright P. Measures of injury severity in childhood: a critical overview. Inj Prev. 1998;4:228-31.

10. Eichelberger MR, Bowman LM, Sacco WJ, Mangubat EA, Lowestein AD, Gotschall CS. Trauma score versus revised trauma score in TRISS to predict outcome in children with blunt trauma. Ann Emerg Med. 1989;18:939-73. 
11. Eichelberger MR, Gotschall CS, Sacco WJ, Bowman LM, Mangubat EA, Lowestein AD. A comparison of trauma score, the revised trauma score and the pediatric trauma score. Ann Emerg Med. 1989;18:1053-55.

12. Ekman R, Welander G, Svanstrom L, Schelp L. Long-term effects of legislation and local promotion of child restraint use in motor vehicles in Sweden. Accid Anal Prev. 2001;33:793-7.

13. Hannan EL, Farrell LS, Meaker OS, Cooper A. Predicting inpatient mortality for pediatric trauma patients with blunt injuries: a better alternative. J Pediatr Surg. 2000;35:155-9.

14. Meredith W, Rutledge R, Hansen AR, Oller DW, Thomason M, Cunningham P, Baker CC. Field triage of trauma patients based upon the ability to follow commands: a study in 29.573 injured patients. J Trauma. 1995;38:129-35.

15. Peclet MH, Newman KD, Eichelberger MR, Gotschall CS, Guzzetta PC, Anderson KD, Garcia VF, Randolph JG, Bowman LM. Patterns of Injury in Children. J Pediatr Surg. 1990; 25: 85 - 90.

16. Randolph LC, Takacs M, Davis K. Resuscitation in the pediatric trauma population: admission base deficit remains an important prognostic indicator. J Trauma 2002;53:838-42.

17. Holland A, Kirby R, Browne GJ, Ross FI e Cass DT. Penetrating injuries in children: is there a message? J Paediatr Child Health. 2002;38:487-91.

18. Arreola-Risa C, Mock CN, Padilla D, Cavasos L, Maier RV, Jurkovich GJ. Trauma care systems in urban Latin America: the priorities should be prehospital and emergency room management. J Trauma. 1995;39:457-62.

19. Nathens AB, Jurkovich GJ, Rivara FP, Maier RV. Effectiveness of state trauma systems in reducing injuryrelated mortality: a national evaluation. J Trauma. 2000;48:25-31.
20. Esposito TJ, Sanddal BS, Reynolds AR, Sanddal ND. Effect of a voluntary trauma system on preventable death and appropriate care in a rural state. J Trauma. 2003;54:663-70.

21. Calkins CM, Bensard DD, Patrick DA, Karrer FM. A critical analysis of outcome for children sustaining cardiac arrest after blunt trauma. J Pediatr Surg. 2002;37:180-4.

22. Cooper A, Barlow B, String D, Ray K, Mottley L. Efficacy of pediatric trauma care: results of a population-based study. J Pediatr Surg. 1993;28:299-305.

23. Hall JR, Reyes HM, Meller JL, Loeff DS, Dembek RG. The new epidemic in children: penetrating injuries. $J$ Trauma. 1995;30:487-91.

24. Potoka DA, Schall LC, Ford HR. Improved functional outcome for severely injuried children treated at pediatric trauma centers. J Trauma. 2001;51:824-34.

25. Poli de Figueiredo LF, Rasslan S, Bruscagin V, Cruz Jr R, Rocha e Silva M. Increase in ticket value and driver license withdrawal score system effectively reduced immediate deaths following trauma in Brazilian roads: first year report of the new traffic code. Injury. 2001;32:91-5.

26. Adekoya N, Thurman DJ, White DD, Webb KW. Surveillance for traumatic Brain Injuries - US, 1989-1998. Morb Mortal Wkly Rep. 2002;51(SS10):1-16.

27. Powell EC, Tanz RR. Adjusting our view of injury risk: the burden of nonfatal injuries in infancy. Pediatrics. 2002;110:792-6.

28. Purvis JM, Hirsch AS. Playground injury prevention. Clin Orthop. 2003;1:11-9.

29. Riddick L, Long WB, Dove DM, Sacco WJ. Automated coding from autopsy reports. Am J Forensic Med Pathol. 1998;19:269-74.

30. Sant'Anna AR, Lopes MJM. Homicídios entre adolescentes na cidade de Porto Alegre, Rio Grande do Sul, Brasil: vulnerabilidade e culturas de gênero. Cad Saúde Pública. 2002;18:1509-17.

\section{Correspondence:}

Simone de Campos Vieira Abib

Rua João Tibiriça, 149

05077-000 São Paulo - SP - Brazil

Phone: (55 11)3836-0730

Fax:(55 11)3862-1539

simoneabib@uol.com.br
Conflict of interest: none

Financial source: none

Received: September 21, 2005

Review: October 19, 2005

Accepted: November 22, 2005

\section{How to cite this article:}

Abib SCV, Schettini ST, Figueiredo LFP. Prehospital pediatric trauma classification (PHPTC) as a tool for optimizing trauma care resources in the city of São Paulo, Brazil. Acta Cir Bras [serial on the Internet] 2006 Jan-Feb;21(1). Available from URL: http://www.scielo.br/acb 